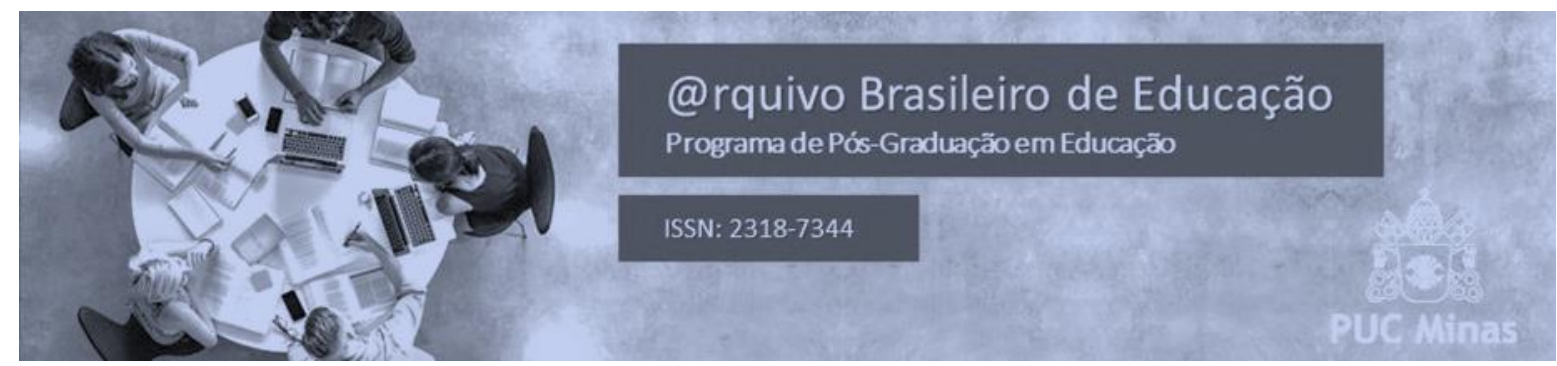

\title{
SIMÓN RODRÍGUEZ: educação e dependência epistemológica na América Latina. Ou inventamos, ou erramos
}

\section{SIMÓN RODRÍGUEZ: education and epistemologic dependence in Latin America. We must invent or err}

José Newton Tomazzoni Tavares Pontifícia Universidade Católica de Minas Gerais (PUC Minas)

\section{RESUMO:}

No presente artigo procuramos mostrar a relação entre Simón Rodríguez, educador venezuelano do século XIX, educação, capitalismo e dependência epistêmica na América Latina. Através dessa aproximação, queremos salientar que, apesar dos processos de independência do início do século XIX, a América Latina ainda vive uma profunda dependência econômica, política, social e cultural que a impede de construir uma sociabilidade própria. Tal sociabilidade original era a questão central do pensamento de Simón Rodríguez. Para o educador venezuelano, a América Latina só poderia trilhar caminho próprio se construísse uma via original no que tange ao processo de conhecimento. Buscamos, também, contribuir para o debate estabelecido na América Latina, desde os anos de 1960, sob a égide da Teoria da Dependência, e interrompido pelas várias Ditaduras, sobre a dependência econômica, cultural, política e social dos países latino-americanos. Dependência, hoje, traduzida sob o império do neoliberalismo.

Palavras-chaves: Simón Rodríguez. Educação. Dependência.

\section{Abstract}

In the present work, we seek to explore the relationship between Simón Rodríguez, a 19th century Venezuelan educator, education, capitalism and epistemic dependency in Latin America. Through this association, we mean to highlight that, despite its independence processes in the early 19th century, Latin America still lives in deep 
economic, political, social and cultural dependence that prevents the building of a sociability of its own - this sociability being the core piece in Rodríguez's thought. For the Venezuelan educator, Latin America could only walk its own footsteps if it were to build its own means regarding knowledge acquisition. Furthermore, we see to contribute to the debate established in Latin America since the 1960s, which was then interrupted by the various Dictatorships, under the framework of the Dependency Theory in regards to the economic, political, social and cultural dependence of Latin American countries - this dependence, today, being regarded and translated to the empire of neoliberalism.

Keywords: Simón Rodríguez. Educational. Dependence. 


\section{INTRODUÇÃO}

Nos debates políticos e nos diversos campos do pensamento social de hoje se percebe uma dificuldade enorme em formular alternativas teóricas e políticas à primazia do Mercado, cuja defesa mais coerente tem sido formulada pelo neoliberalismo. Essas dificuldades se devem, ao nosso ver, ao fato de que o neoliberalismo é combatido como se fosse apenas uma teoria econômica. Aos olhares dos críticos do neoliberalismo, o capitalismo é apenas uma teoria econômica, quando na verdade ele é uma rede de poder muito mais ampla que abrange vários setores da vida social. O capitalismo, assim entendido, é, portanto, um discurso hegemônico de um modelo de civilização, ou seja, uma síntese de pressupostos e valores básicos da sociedade liberal moderna em torno do ser humano, da riqueza, da natureza, da história, do progresso, e do conhecimento.

Tal rede de poder mostra sua eficácia maior quando naturaliza as relações sociais. Sua força está na noção segundo a qual as características chamadas modernas, leia-se: liberais e neoliberais, são a expressão de uma tendência espontânea, natural do desenvolvimento histórico. Desta forma, tudo se passa como se a lógica do mercado e do trabalho abstrato fosse o fim da história da humanidade, ponto de chegada óbvio do desenvolvimento da história universal, e, portanto, a referência básica na qual devemos nos acomodar.

Adam Smith, considerado o pai do Liberalismo econômico, em 1776, em seu livro “A Riqueza Das Nações”, mostra-se profundamente encantado com a pujança do comércio na Inglaterra no século XVIII. Embora conhecendo a realidade asiática, nada falou o pensador escocês da grandiosa rede de comércio chinesa que vigorava havia mais de seiscentos anos nas estepes asiáticas e que representava dez vezes mais o volume de trocas comerciais que se davam na "exuberante” Europa de Smith. Para ele a China estava adormecida. Não quis expressar o filósofo moral que aquilo que ele via como a grande novidade inglesa não passava de esquálida reprodução incipiente de uma grandiosa rede de comércios e trocas que existia no mundo muçulmano e chinês a leste do solo europeu.

O filósofo Friedrich Hegel, um século depois, constrói sua filosofia amparada na ideia central de que o "Espírito Absoluto" tem sua trajetória de constituição partindo do oriente em direção ao ocidente, rumo à Europa civilizadora, lugar onde o Espírito 
alcança sua maior expressão ao unir-se consigo mesmo. A Europa seria, assim, o fim e centro do mundo. O Oriente seria o começo, a pré-história da verdade europeia. Nada sabia o filósofo alemão, ou não quis dizer, da profundidade do pensamento indiano e chinês que vigorava havia séculos nas margens de lá do rio amarelo ou da florescente atividade intelectual dos muçulmanos, sem a qual nada saberia a Europa de filosofia. Para ele tudo isso era apenas um balbuciar incipiente de um pensamento rudimentar. A infância do Espírito.

Também nada sabia o erudito professor de Jena que a Grécia antiga, inspiração do pensamento ocidental eurocêntrico, era, na verdade, parte do mundo oriental. A mitológica Europa é, portanto, filha de fenícios, semita então. Não sabia que a Europa futura "definitiva", a qual ele achava ser o centro do mundo, estava situada ao Norte da Macedônia e ao norte da Magna Grécia na Itália. Essa Europa estava ocupada pelo "bárbaro" por excelência até 1492, de maneira que posteriormente usurpará um nome que não lhe pertence, porque a Ásia e a África eram as culturas mais desenvolvidas até então, e os gregos clássicos tem plena consciência disso. Mas nada sabe disso o autor de "Fenomenologia do Espírito".

Max Weber, no início do século XX, se perguntava quais eram os encadeamentos de circunstâncias que tinham produzido no Ocidente e, só no Ocidente, fenômenos culturais que estavam numa direção evolutiva de significado e validade universais. Também o sociólogo alemão acreditava que nada havia de validade universal fora do solo Europeu antes da Europa moderna. Encantou-se, o teórico da neutralidade, que deu aval a conferência de Berlin, onde a Europa fatiou a África a seu bel prazer, com a imensa superioridade europeia sobre os outros continentes. Como se a Europa tivesse, a partir de condições eminentemente internas, se constituído no centro do mundo.

Mas não foi assim. Até 1492 a Europa, decantada pelos pensadores modernos como o centro do mundo, não passava de periferia do mundo asiático-muçulmano. Em nada era a Europa superior a eles. A transformação da Europa em centro do mundo se deu pela constituição de sua centralidade em proporção direta a constituição de suas periferias. Foi a descoberta da América que deu a Europa vantagens comparativas para se impor diante do mundo asiático-muçulmano de então. A partir do ouro ameríndio a então periférica Europa começa a gestar sua centralidade no sistema mundo. $\mathrm{O}$ centro mediterrâneo perdia sua plasticidade para o atlântico. Nascia a Modernidade. (DUSSEL, 2002). 
É esse ponto de chegada europeu: sociedade sem ideologias, modelo civilizatório único, globalizado, universal, politicamente desnecessário, que questionamos a partir do pensamento educacional de Simón Rodríguez. A busca de alternativas à conformação profundamente excludente e desigual do mundo moderno, exige um esforço de desconstrução do caráter universal e natural da sociedade capitalistaliberal-eurocêntrica. Esse esforço requer um questionamento das pretensões de objetividade e neutralidade dos principais instrumentos de naturalização e legitimação desta ordem social

O pensamento de Simón Rodríguez se insere nesse contexto. Profundamente enraizado na cultura de seu povo, o maestro caraquenho desde as primeiras horas do seu pensamento orientou sua vida intelectual por uma coisa só: como transformar a América Latina em uma Pátria Grande democrática, popular e original. Pensando em um momento de bifurcação da realidade latino-americana, onde se começava a forjar a identidade dos povos deste continente, ele tomou o partido das massas despossuídas. Contra um liberalismo excludente de feição eclética, ele postulou uma sociedade absolutamente original para os moldes de então. Algo que somente no final do século XX começou a ser pensado na América Latina como sistema e que recebeu o nome de Filosofia da Libertação e Pensamento Decolonial.

\section{A MODERNIDADE E O EUROCENTRISMO}

A questão da Modernidade se torna crucial para a compreensão do nosso continente. A ideia que se tem dela modifica substancialmente nossa compreensão de nós mesmos no contexto mundial. A descoberta do ser latino-americano passa necessariamente por uma nova leitura do processo de constituição da Modernidade. É dela que deriva uma visão de Cultura, de Moral, de Estado, de Instituições Políticas etc... Compreender nosso verdadeiro lugar nessa geopolítica é fundamental para o estabelecimento de uma nova prática social e, dentro dessa, uma nova prática educacional. Como momento do processo eurocêntrico, e educação teve e tem um papel fundamental para a manutenção da ordem estabelecida pelo "centro do mundo".

Nesse sentido o pensamento de Enrique Dussel, consubstanciado na sua "Filosofia da Libertação" nos ajuda a entender o nosso verdadeiro lugar nessa geopolítica contemporânea. Para o pensador argentino é preciso distinguir duas visões 
de Modernidade. A primeira, desde um horizonte eurocêntrico, propõe que a Modernidade seja um fenômeno exclusivamente europeu. Um processo que vai se desenvolvendo desde a Idade Média e se difunde posteriormente em todo o mundo. Para esse paradigma de Modernidade a Europa teria tido características excepcionais internas, que permitiriam que ela superasse, por sua racionalidade, a todas as outras culturas. Segundo essa visão, o espírito da Europa é a verdade absoluta que se determina ou se realiza por si mesmo sem dever nada a ninguém. Esse paradigma eurocêntrico foi o que se impôs no mundo intelectual da periferia mundial. Romper com esse paradigma é fundamental para o estabelecimento de uma educação crítica no continente. (DUSSEL, 2002)

A cronologia dessa cosmovisão tem a sua geopolítica. A subjetividade moderna se desenvolveria espacialmente desde a Itália do Renascimento, a Alemanha da Reforma e da Ilustração, até a França da Revolução Francesa. Tudo isso se trataria da Europa central.

A segunda visão de Modernidade, partindo do que Dussel chama de "paradigma mundial", concebe a Modernidade como a cultura do centro do "sistema mundo", o primeiro sistema mundo, pela incorporação da América, e como resultado da gestão dessa centralidade. Assim, para Dussel, a Modernidade europeia não é um sistema independente, autorreferente, mas uma parte do sistema mundo: seu centro.

A Modernidade seria, assim, um fenômeno que vai se mundializando: começa pela constituição simultânea da Espanha com referência à sua periferia. Esse é o momento da primeira modernidade, no dizer de Dussel, que será esquecida quando o centro se transferir para a Holanda, França, Inglaterra. Assim, a Europa irá constituindo-se em centro sobre uma periferia crescente. A Modernidade seria, então, para esse paradigma mundial um fenômeno próprio do "sistema" com "centroperiferia”. Tal descoberta é fundamental para o estabelecimento de uma ciência social/humana crítica na América Latina.

Tal concepção de Modernidade se assenta em uma tese fundamental: a centralidade da Europa no "sistema-mundo" não é fruto somente de uma superioridade interna acumulada na Idade Média europeia sobre as outras culturas, mas também e principalmente, o efeito do fato do descobrimento, conquista, colonização e integração da América, que dará à Europa a vantagem comparativa determinante sobre o mundo otomano-muçulmano, a Índia e a China. 
Posteriormente, e isso será fundamental para nossa análise, essa gestão da centralidade do "sistema-mundo" vai permitir à Europa se transformar na "consciência reflexa", - leia-se: a filosofia moderna -, da história mundial, produzindo, assim, muitos valores, invenções, descobrimentos, tecnologias, instituições políticas e, no nosso caso específico, uma ideia de uma educação para o outro que se atribui a si mesmo como sua produção exclusiva que será imposto à periferia como a verdade absoluta.

É essa Modernidade e essa noção de educação eurocêntricas que colocamos em dúvida sob o olhar do pensamento de Simón Rodríguez. Ao se constituir como centro, negando tudo que não é Europa, o processo educacional promovido por essa Modernidade nega o ser latino-americano considerando-o como bárbaro. Os jovens latino-americanos, desde a conquista até hoje, devem deixar o seu "mundo" para serem educados com base nos fundamentos da cultura europeia/norte-americana. Uma rápida olhada nos currículos das nossas Universidades, em qualquer parte do Brasil, do Oiapoque ao Chuí, mostra a veracidade dessa afirmação: a maior parte dos autores estudados em nossos cursos de ciências, filosofia e educação são europeus/norteamericanos e, “coincidentemente", os mesmos.

A lógica eurocêntrica ainda é avassaladora em nossos sistemas de ensino. Nas Universidades brasileiras os estudantes são quase obrigados a conhecer apenas autores europeus ou norte-americanos. Pensadores como o colombiano Orlando Fals Borda, o boliviano René Zavalleta, o venezuelano Ludovico Silva, o peruano Aníbal Quijano, o argentino Enrique Dussel entre outros, são desconhecidos do mundo acadêmico brasileiro. Segundo a lógica eurocêntrica dominante em nossa cultura, o que poderia vir de bom da Bolívia, Venezuela, Peru ou Argentina?

Não se trata de negar o conhecimento historicamente acumulado e nem de desmerecer a contribuição que autores de outras partes do mundo possam dar. Tratase, ao contrário, de criarmos a nossa identidade a partir das nossas referências culturais e intelectuais. O sociólogo brasileiro Alberto Guerreiro Ramos já nos advertia nos anos de 1950 da necessidade de uma "redução sociológica" nas ciências sociais para superarmos esse eurocentrismo e colonialismo cultural. Passados quase sessenta anos da sua advertência ainda estamos enredados na mesma problemática. A forte influência do pensamento europeu e norte-americano nas nossas Universidades mostra o nível elevado de colonialismo cultural e intelectual que nos encontramos. Não estaria na hora de uma "redução educacional”? 
Portanto, a desconstrução dessa presença eurocêntrica como hegemônica é o ponto central para o estabelecimento de um processo educacional crítico. Processo esse que nos levaria a uma produção intelectual própria, relevante para o confronto com uma realidade latino-americana dependente e subdesenvolvida.

\section{SIMÓN RODRÍGUEZ E A EDUCAÇÃO PARA A ORIGINALIDADE}

Encontramos em Simón Rodríguez uma das primeiras bases teóricas sistemáticas para o questionamento desse processo eurocêntrico na América Latina. Há no maestro caraquenho uma antecipação das questões propostas pelos educadores críticos do século XX no nosso continente. Adiantou-se o venezuelano na percepção de que a dependência era o cerne da questão, e que o continente latino-americano teria que forjar um pensamento próprio sob pena de manter ou aprofundar os laços de pertença aos grilhões estrangeiros. Para o pensador caraquenho não havia dúvidas: “ou inventamos ou erramos". (RODRÍGUEZ, 2016).

Simón Narciso Rodríguez nasceu em Caracas, capital da Venezuela, em 1769 ou 1771. Veio ao mundo como uma criança abandonada. Seus pais verdadeiros se perderam para sempre. Seus biógrafos afirmam ter ele sido encontrado em algum lugar e criado por Cayetano Carreno e Rosália Rodríguez, cujo sobrenome Simón adotou. Teve um irmão chamado Cayetano que, ao contrário de Simón, adotou o sobrenome paterno. Seu pai morreu ainda jovem e Simón e seu irmão ficaram sob a tutela de um tio, o presbítero Rodríguez - um sacerdote católico muito respeitado - que se encarregou da educação de ambos.

Leitor voraz, ainda bem jovem Simón Rodríguez conheceu autores importantes, ligados as novidades que vinham da Europa, como Rousseau, seu preferido. Iniciou sua carreira de educador em Caracas, na Venezuela, com pouco mais de 20 anos, garantindo um posto numa escola local em Caracas. Desde ali, já era original. É histórico o texto: Reflexiones sobre los defectos que vician la escuela de primeras letras de Caracas y médios de lograr su reforma por um nuevo establecimiento escrito em 1794, quando era ainda bem jovem, e no qual faz críticas à educação da época e aponta caminhos novos para esse fazer. Pouco depois, decepcionado com o conservadorismo educacional e o desfecho de uma insurreição contra a metrópole, ele parte para a Europa. Apaixonado por Rousseau, ele encontra na nascente vida 
republicana europeia o viço para desenvolver seu pensamento.

Andarilho, ele criou escolas em todos os lugares por onde passou: França, Espanha, Itália, EUA, Rússia. Depois, no encalço de seu jovem pupilo, Simón Bolívar, ele retornou à América e se deparou com um mundo caótico, colonial, oprimido, explorado. Esse enfrentamento causou-lhe uma explosão interna. A formação liberal europeia, em confronto com a paupérrima condição de seus irmãos americanos, gestou nesse educador a busca por uma síntese criadora. Percebeu, talvez, pela dor nos rostos sofridos de seus irmãos, que não era possível transferir pura e simplesmente o liberalismo para o mundo hispano-americano. Em busca da construção de uma outra filosofia, de uma síntese geradora do novo, ele propôs algo até então inédito: uma via própria, nossa, autóctone. Esse pensamento original se condensava em um dos seus mais famosos aforismos: "ou inventamos ou erramos". Tinha, a partir da experiência vital dos povos latino-americanos, a certeza de que a América Latina precisava trilhar um caminho próprio. E a educação era para esse caraquenho o fio condutor de uma nova forma de organização social.

A educação escolar proposta por Simón Rodríguez partia de uma constatação de fundo: a necessidade de uma América Latina independente, não apenas politicamente, mas, principalmente culturalmente e, consequentemente, economicamente. Razão pela qual, para o maestro caraquenho, não havia separação entre educação e política. Rodríguez percebeu desde as primeiras horas de uma América independente politicamente que as relações sociais existentes, derivadas da colônia, não permitiam uma sociabilidade democrática e autônoma. A simples importação do liberalismo europeu não mudaria o quadro de pobreza e dependência. Ao contrário, o aumentaria.

O maestro venezuelano percebeu de imediato o problema central do mundo hispano-americano. Os homens que fizeram o movimento de independência em toda a América espanhola, e particularmente na Venezuela, tinham um modelo que tentavam implementar: o liberalismo estadunidense e europeu. Tal modelo continha instituições que não tinham antecedentes na América Latina. Os povos latinoamericanos nunca haviam vivido em República ou em nenhum outro regime democrático. Durante os 300 anos de regime colonial neste continente não houve liberdade, igualdade ou qualquer forma de representação política. De tal modo que queriam instaurar instituições para as quais os povos latino americanos não estavam preparados. Simón Rodríguez denunciou o erro fundamental de querer transplantar 
instituições estrangeiras que não coincidiam com a natureza, o caráter, o passado e a realidade social latino-americana.

A originalidade de Simón Rodríguez é que ele se dá conta desse problema fundamental. Encontra uma saída, propõe uma solução e inaugura uma maneira de criar uma nova ordem. Quando regressa a América em 1823 ele se põe o que acreditava ser o problema central: como organizar os países latino-americanos para que pudessem se desenvolver pacificamente em um regime que garantisse uma República democrática.

Estava feita a independência política. A luta militar já havia triunfado. O grande sonho de Bolívar, feito no Monte Sacro, de libertar a América Latina, havia se cumprido. Mas se punha, então, o imenso problema de como organizar esses países que vinham de 300 anos de um regime que nada tinha de republicano. Países que não tinham Instituições próprias e que fatalmente poderiam cair nas mãos de caudilhos armados, como realmente caíram.

Simón Rodríguez tem uma resposta para isso. Não era possível retornar à Monarquia e, ao mesmo tempo, devido à incompatibilidade das instituições sociais existentes, também não era possível uma República naquele momento. Os 300 anos de colonialismo impediam a instauração imediata de uma República democrática. Segundo o mastro caraquenho ela estava destinada a fracassar. A esse dilema Rodríguez dá sua resposta. Se não era possível regressar à Monarquia e também não se podia implementar imediatamente a República, o que se poderia fazer? A resposta não era outra: encontrar uma via própria.

A via própria encontrada por Rodríguez partia da ideia de que a América Latina tinha uma singularidade, uma realidade peculiar, uma originalidade. É dessa originalidade que deveria partir os conceitos de suas instituições. Não tínhamos que imitar ninguém. Tínhamos que construir nossa convivialidade a partir de nossa própria realidade, não para se conformar com ela, mas para transformá-la em uma base realista e efetiva. Tal afirmação se condensava em seu mais famoso aforisma: "ou inventamos, ou erramos”.

Para fazer isso, Rodríguez encontra o que, para ele, era o instrumento ideal: a escola. Não temos republicanos, dizia ele, mas queremos uma República. Como resolver essa contradição? A saída encontrada foi fazer o republicano através da escola. Assim, Rodríguez concebe uma escola que tinha pouco a ver com a escola de então. 
Uma escola que ensinasse a transformação social. Não só uma escola que ensinasse o tradicional: a ler, escrever e contar ou ciências naturais, mas uma escola em que se ensinasse a viver em república. Uma escola em que a disciplina mais importante seria uma nova sociabilidade.

A escola modelo de Rodríguez intentava reunir as crianças para ensinar a viver em pequenas sociedades em uma espécie de ensaio de República através da vivência da responsabilidade, dos direitos e deveres com noções de obrigações com os demais. A ideia do social permeava todo seu processo educativo. Tal escola buscava uma formação que integrava o trabalho intelectual com o trabalho manual, para que ao sair dela, os alunos pudessem ser as bases de um sistema republicano verdadeiro. Rodríguez postulou a omnilateralidade bem antes que Karl Marx e Friedrich Engels.

Tal escola modelo continha um conceito original de cidadania que contrastava com o modelo vigente. Este, devedor do Iluminismo, pretendia estabelecer a figura do cidadão ilustrado, capaz de pensar em forma autônoma. A independência do juízo, expressada na pessoa ilustrada era a combinação mais importante para o acesso à cidadania. A ilustração garantia a absoluta responsabilidade daquele que votava, e que por sua própria condição o habilitava a pensar reflexivamente seu voto. Para que isso acontecesse era necessário que o cidadão não só soubesse ler e escrever, como também pudesse ganhar a vida sem estar sujeito a outra pessoa por laços de servidão. Era a cidadania liberal onde o saber e a propriedade eram considerados como as condições necessárias para assegurar a independência do juízo e ação do indivíduo cidadão.

A teoria liberal de cidadania tem como pressuposto que os homens são iguais e livres por natureza. As desigualdades sociais seriam apenas o desdobramento da igualdade e da liberdade naturais. A origem dos conflitos estaria na busca de realização pessoal, exigência da própria liberdade e igualdade naturais. Devido a esses conflitos gerados pela própria naturalidade humana, se faria necessário o Estado para garantir os limites e assegurar a sobrevivência da própria humanidade. Nessa visão liberal, a desigualdade social não é apenas legítima, mas constitutiva do mundo humano. Razão pela qual suprimi-la seria impossível. No máximo coibir seus excessos.

Para Rodríguez, ao contrário, não havia condição alguma que limitasse o acesso à cidadania. Nela havia elementos tão originais que, não só não podiam ser explicados com os saberes de então, como também interrompia, questionava e modificava todo um estado de coisas petrificados pela estrutura colonial. Sua concepção de cidadão 
supunha um novo ordenamento de tudo que havia, e inaugurava uma nova forma de relação política entre os homens. (DURÁN 2010). Para Rodríguez, a cidadania não era o resultado que se obtinha ao final de um largo processo, apenas para diminuir e não suprimir os excessos da liberdade e igualdade, como propunha o liberalismo, mas, ao contrário, era algo que estava no princípio e que se originava em uma ruptura com a ordem estabelecida.

Assim, o conceito de igualdade do qual partia se afastava muito do conceito de igualdade da cidadania vigente sustentada pelas elites ilustradas da América. Para Rodríguez a igualdade era um axioma a partir do qual derivava uma conduta e não um programa. A igualdade não era algo a conseguir pelos supostos desiguais, mas um princípio de qual partia. Para o maestro caraquenho a igualdade não era um conceito a ser demonstrado, senão um nome cujas consequências se verificavam em cada um de seus atos. Essa talvez seja a grande diferença de Rodríguez: sua escola partia da igualdade e não da desigualdade. Ela não se propunha a formação de cidadãos através da nivelação das desigualdades, como ocorre no liberalismo. Para Rodríguez todos deviam ir à escola porque eram cidadãos e não o contrário. $\mathrm{O}$ conceito de soberania popular informava todo o pensamento de Simón Rodríguez.

\section{A ATUALIDADE DE SIMÓN RODRÍGUEZ E A REALIDADE LATINO- AMERICANA.}

Porque recuperar Simón Rodríguez em pleno século XXI? O que teria a nos dizer esse caraquenho solitário e sonhador do século XIX? Há algumas razões. No brasil ele é quase desconhecido. A carga eurocêntrica que se abate sobre nós é por demais acentuada. Pensadores latino-americanos não tiveram espaços de presença questionadora em uma boa parte de nossa realidade acadêmica e política. Nosso país sempre esteve, preponderantemente, de costas para os Andes. Sempre tivemos dificuldade de nos vermos como pertencentes ao mundo latino-americano. Somente hoje, nas últimas décadas, o Brasil começa a descobrir-se habitante de uma cultura latino-americana, mas ainda é um processo lento.

Em outros países da América Latina, o pensamento de Simón Rodríguez vem sendo recuperado desde o início da segunda metade do século XX e mais fortemente a partir da primeira década do nosso século, quando alguns países do continente 
começaram a forjar a busca de uma outra forma de convivialidade e a gestar políticas dissonantes da política neoliberal vigente, entre eles a Venezuela, terra natal de Rodríguez.

Sua reaparição não foi fruto do acaso. A tentativa de superar o neoliberalismo nesses países da região a partir do final do século passado foi resultado de anos de construção de um pensamento latino-americano próprio. Nada se deu por geração espontânea. Enquanto o Brasil estava predominantemente de costas para a América Latina, preocupado em copiar a França e os Estados Unidos, alguns países de língua espanhola, seguindo a grande tradição de libertação de Simón Bolívar, nunca esqueceram suas raízes e, por isso, estavam empenhados em construir uma nova sociabilidade. Segundo Enrique Dussel, um dos maiores expoentes da Filosofia da Libertação, os antecedentes primeiros de um pensamento libertador no continente já se encontravam em Bartolomeu de Las Casas, ainda no tempo da conquista. Mas é em José Carlos Mariátegui, pensador peruano do início do século $\mathrm{XX}$, que o filósofo argentino credita os inícios modernos de um pensar latino-americano próprio.

A partir daí, e especialmente a partir da segunda metade do século XX, há na América Latina um novo despertar da consciência crítica. A Teoria Marxista da Dependência, a Teologia da Libertação, juntamente com a Sociologia e a Filosofia da Libertação, inauguram um novo tempo do pensamento latino-americano. Tais correntes teóricas expressavam as lutas e os anseios de libertação das gentes pobres e exploradas desse continente.

Dessa forma, a América Latina nunca esteve adormecida. As lutas por libertação sempre estiveram no horizonte dos povos latino-americanos. Apesar da mão forte do colonialismo as gentes desse continente nunca se resignaram. Em todos os rincões da América povos inteiros nunca esqueceram o sonho de Bolívar. Embora tais lutas nunca tiveram a visibilidade que merecem, devido a monumental presença da ideologia liberal e neoliberal na região, elas sempre estivem atuantes na construção de um outro mundo possível.

Mas essa não é a única razão da recuperação do pensamento de Simón Rodríguez. O nosso olhar sobre o educador caraquenho parte de uma realidade especificamente educacional, portanto, o nosso intento é mostrar a importância do maestro venezuelano para o mundo educacional latino-americano contemporâneo. E qual seria essa importância? 
Durante as décadas de 1980 e 1990 pulularam na literatura educacional brasileira e latino-americana críticas ao projeto neoliberal de educação. Tal projeto, segundo esses críticos, tinha por intenção a transformação da educação em um mercado educacional, seguindo as pegadas de uma política de desobrigação do Estado para com as políticas públicas. Basicamente essa era a crítica: a educação não deveria ser um bem de consumo, mas um direito do cidadão que o Estado devia proteger e assegurar.

Assim, o alvo era o projeto denominado neoliberal. Tal projeto origina-se basicamente a partir de dois grandes textos fundadores: "O caminho da servidão" de Friedrich Hayek, escrito em 1944, onde o autor firma-se contra o planejamento econômico coletivista do Estado, e o relatório produzido por um grupo de cidadãos privados dos EUA, Europa e Japão, com a finalidade de avaliar os problemas de governabilidade que aquelas sociedades estavam enfrentando sob o regime da democracia representativa, denominado "The crisis of democracy", de 1975.

Quando, em meados dos anos 1970, se dão as condições para o resgate das ideias liberais, esses textos vêm à luz com força total para iluminar o novo momento do modo de produção capitalista, ou seja, recuperar o ânimo do capitalismo via dinamização da economia de mercado. Os dois textos em questão, embora em contextos diferentes, propõem um objetivo comum: resgatar a concepção de Estado que caracterizou o pensamento liberal dos séculos XVIII e XIX e que ressurge no cenário atual encarnada em uma expressão: Estado mínimo.

O estabelecimento desse "Estado mínimo" expressou uma série de transformações ocorridas no sistema capitalista, com destaque para o crescimento cada vez mais acentuado das operações financeiras em ritmos superiores ao crescimento da riqueza real, mensurada pelo Produto Interno Bruto e do nível de investimentos em atividades diretamente relacionadas à esfera da produção. Essas transformações foram uma tentativa, engendrada pelos detentores do capital, para superar uma crise estrutural do sistema capitalista que se manifestou desde o final dos anos 1960. Essa crise, hoje acentuada, implicou uma crescente dificuldade de ampliação do processo de valorização do capital na esfera produtiva.

Nossa tese é de que tais críticas a essa lógica cobrem apenas uma parte do problema: a causa próxima. O projeto neoliberal privatizante é apenas a consequência e expressão atual de um projeto maior que se abate sobre nós desde os tempos da 
conquista. O BIRD, FMI, Banco Mundial e todos os organismos internacionais que implementam o projeto atual de políticas neoliberais são apenas os operadores contemporâneos do processo. Concordamos com tais críticas, mas acreditamos que o problema central da questão educacional na América Latina, assim como em todo o mundo periférico e dependente, parte de um ponto anterior e mais profundo: o eurocentrismo e suas consequências: o colonialismo e a colonialidade. Em suma: a lógica do capital.

Aníbal Quijano distingue ambos os termos. Para ele colonialidade é um conceito diferente, ainda que vinculado ao conceito de colonialismo. Este último se refere estritamente a uma estrutura de dominação e exploração, onde o controle da autoridade política, de recursos de produção e de trabalho de uma população é determinada por outro com uma identidade diferente e cuja sede também está em outra jurisdição territorial. O colonialismo, portanto, é mais antigo. No entanto, a colonialidade tem provado ser, nos últimos quinhentos anos, mais profunda e duradoura que o colonialismo. Para Quijano o conceito de colonialidade transcende as particularidades do colonialismo histórico e não desaparece com a independência ou descolonização. Pelo contrário, deita raízes mais profundas porque domina por fatores que ultrapassam a força bruta, entre eles o cultural e o epistemológico. (QUIJANO 2015)

Essa distinção entre colonialismo e colonialidade permite, portanto, explicar a continuidade das formas coloniais de dominação, mesmo após o fim das administrações coloniais, além de demonstrar que essas estruturas de poder e subordinação passaram a ser reproduzidas pelos mecanismos do sistema-mundo capitalista colonial-moderno. Dessa forma, a noção de colonialidade atrela o processo de colonização das Américas à constituição da economia-mundo capitalista, concebendo ambos como partes integrantes de um mesmo processo histórico iniciado no século XVI.

É preciso, portanto, diferenciar e analisar o novo modelo colonial que se configura quando o antigo, o da distribuição de renda internacional, se esgotou. $\mathrm{O}$ capitalismo mundializado passou a aplicar novos mecanismos de apropriação do excedente periférico pela via das empresas transnacionais e do sistema financeiro especulativo, aliando-se às elites emergentes locais. Ruy Mauro Marini nos adverte da diferenciação entre a situação colonial e a situação dependente. (MARINI, 1973) 
O conceito de decolonialidade, assim, se torna útil para transcender a suposição de certos discursos acadêmicos e políticos, segundo os quais, com o fim das administrações coloniais e a formação dos Estados-nação na periferia, vivemos agora em um mundo descolonizado e pós-colonial. Partimos, ao contrário, do suposto que a divisão internacional do trabalho entre centro e periferia, assim como a hierarquização ético-racial das populações, formada durante vários séculos de expansão colonial europeia, não se transformou significativamente com o fim do colonialismo e a formação dos Estados-nação na periferia. Assistimos, ao contrário, uma transição do colonialismo moderno à colonialidade global, processo que tem transformado as formas de dominação implantadas pela modernidade, mas não as estruturas das relações centro-periferia. Sem nunca esquecer que essa transição e reprodução da colonialidade é feita pelo imperialismo/imperialidade. É nesse contexto de ressignificação das estruturas de dominação baseada na colonialidade global, expressando uma nova forma de dependência dos países latino-americanos, que entendemos a pertinência do pensamento de Simón Rodríguez.

Tal colonialidade global tem como eixo articulador central a ideia de Modernidade, noção que captura, segundo Edgard Lander (2000), quatro dimensões básicas: 1) A visão universal da história associada à ideia de progresso (a partir da qual se constrói a classificação e hierarquização de todos os povos, continentes e experiências históricas); 2) a naturalização tanto das relações sociais como da natureza humana da sociedade liberal-capitalista; 3) a naturalização ou ontologização das múltiplas separações próprias dessa sociedade; e 4) a necessária superioridade dos conhecimentos que essa sociedade produz (ciência) em relação a todos os outros conhecimentos.

Essa última característica da Modernidade nos interessa mais de perto. De fato, com o desenrolar dos séculos, o colonialismo se consolidou na América Latina de tal forma que mesmo com as independências e formação de Estados Nacionais, a lógica colonial permaneceu nas estruturas sociais, imbricada com a expansão e impacto do imperialismo e do capitalismo no subcontinente. Esta lógica, que foi construída no imaginário dos colonizados ao longo do tempo, se naturalizou na forma de uma colonização internalizada. O que resulta desse longo processo é claramente visível nos dias de hoje. Como exemplo temos a manutenção de uma colonialidade do poder e uma 
dependência cultural (não apenas social e econômica), que implicam na hegemonia eurocêntrica como perspectiva de conhecimento.

Nesse contexto de colonialidade de poder, as populações dominadas têm suas identidades submetidas à hegemonia eurocêntrica, que define o que é conhecimento. Assim, o imaginário construído ao longo da formação de um sistema colonial/moderno resulta na mutilação epistemológica, a partir da dominação hegemônica do pensamento eurocêntrico, que segundo Grosfoguel (2016), se configura a partir pensadores de apenas cinco países - França, Alemanha, Itália, Inglaterra e EUA-, restringindo progressivamente a ecologia de saberes e estabelecendo linhas abissais entre eles. (Santos, 2010).

Assim, percebe-se que, ao longo da Modernidade foi se estabelecendo uma soberania em relação à forma como se pensava e se produzia o conhecimento. Essa soberania era pautada em modelos epistemológicos hegemônicos dentro da ciência moderna de forma a tornar subalterno as formas consideradas desviantes daquela institucionalizada, impedindo sua emergência ou cerceando seu desenvolvimento. Tal ciência moderna de feição gnosiológica, tendo o sujeito como polo regente do conhecimento, baseada no "eu” cartesiano, toma de assalto tudo que é considerado não moderno.

Segundo Quijano (2005), ao contemplarmos a relação intrínseca entre modernidade e colonialidade, é difícil não pensar nas relações entre nações na modernidade sem levar em consideração a dimensão colonial. É pari-passu com a modernidade e o imperialismo colonial das nações europeia, associados intrinsecamente à expansão do capitalismo, que a colonialidade do poder e do saber se originam.

Portanto, nossa tese central se ancora no pressuposto de que o problema central que se coloca para a América Latina, hoje, não é a disjunção ditadura/democracia e, sim, dependência/Libertação. Segundo nossa interpretação essa é a questão de fundo fundamental que perpassa todas as dimensões da sociabilidade latino-americana. A educação, como uma das dimensões dessa sociabilidade, está profundamente marcada por essa determinação colonial e dependente que caracteriza a sociabilidade capitalista latino-americana. Assim, é só com a superação dessa forma de sociabilidade que será possível uma educação que prime verdadeiramente pela emancipação humana. 


\section{COLONIALISMO E EDUCAÇÃo}

Acreditamos que pensar o processo educacional nessa quadra histórica equivale a pensa-lo, não só dentro das políticas neoliberais que nascem na segunda metade do século $\mathrm{XX}$, mas, e principalmente, dentro de um contexto mais amplo caracterizado pela convergência do capitalismo, colonialismo e eurocentrismo que elegem um tipo de conhecimento como oficial, encabeçado por um tipo de ciência oficial: a moderna, negando e desconsiderando outras formas de saber. Tal desconsideração faz parte de um projeto maior de controle do capitalismo central sobre suas periferias. No limite, a questão relevante é o questionamento sobre as bases sociais da produção do conhecimento.

A questão que se coloca como central para um país periférico e dependente como o nosso é a seguinte: $\mathrm{O}$ que acontece quando a produção imaterial, e não mais a produção material associada com o industrialismo, se coloca no centro das políticas de desenvolvimento? Pensamos que essa pergunta não é inocente e na verdade encerra as causas profundas do nosso subdesenvolvimento científico e tecnológico. Toda a lógica educacional de fundo que atravessa as políticas públicas para o setor, não só no Brasil, mas em todos os países dependentes, está banhada por essa determinação. Razão pela qual pensar a educação no mundo contemporâneo significa pensá-la dentro desse contexto maior que remonta à constituição da Modernidade/Eurocentrismo e seu colonialismo epistêmico.

Durante as décadas de 1960 e 1970 os Estados Nacionais definiram o desenvolvimento dos países considerados de terceiro mundo por referência aos indicadores de industrialização. Pensava-se que o desenvolvimento econômico dependia do crescimento da indústria, de tal forma que o subdesenvolvimento correspondia a uma etapa histórica pré-industrial. Sair do subdesenvolvimento equivalia a promover o desenvolvimento do setor industrial, o qual redundaria em um aumento do ingresso per capita, dos índices de alfabetização e escolaridade, da esperança de vida etc...Assim pensou o desenvolvimentismo da CEPAL.

Para os desenvolvimentistas o que se tratava era de gerar o trânsito da sociedade "tradicional" para a sociedade "moderna" pois se supunha que a modernização representava um contínuo no qual o subdesenvolvimento era uma fase inferior do desenvolvimento pleno. 
Tal ideia de modernização se converteu no objetivo central dos Estados asiáticos, africanos e latino-americanos durante décadas. Nesse contexto se fazia urgente a intervenção do Estado em setores chaves como a saúde, a educação, a urbanização etc...Tudo isso fazia parte de uma estratégia desenhada pelo Estado para criar as condições industriais que permitiriam eliminar a pobreza e levar o desenvolvimento a todos os setores da sociedade. A teoria da dependência de corte marxista desvelou essa falácia.

Em meados da década de 1980, com a recomposição do modo de produção capitalista, essa ideia de desenvolvimento industrial se debilitou e começou a ser transformada por outra ideia diferente: o desenvolvimento sustentável. Arturo Escobar assim explica essa transformação:

\begin{abstract}
La ideia de desarrollo, al parecer, está perdendo parte de su fuerza. Su incapacidade para cumplir sus promesas, junto con la resistência que le oponen muchos movimentos sociales y muchas comunidades, está debilitando su poderosa imagen: los autores de estúdios críticos intentan a través de sus análises dar forma a este debilitamiento social y epistemológico del desarrollo. Podría arguirse que si el desarrollo [industrial] está perdendo empuje es debido a que una es imprescindible para las estratégias de globallización del capital (ESCOBAR, 1999, pg. 128)
\end{abstract}

Segundo Escobar, o capital estaria sofrendo uma mudança significativa em sua forma e adquirindo, aos poucos, um rosto "pós-moderno". O que Escobar chama de "pós-moderno" é a característica capitalista contemporânea resultante de um novo padrão de acumulação centrado no poder das instituições financeiras, tendo como agentes principais os bancos, os fundos de pensão, os fundos de investimentos, as seguradoras e outras empresas financeiras especializadas.

Isso significa que aspectos que o desenvolvimento moderno havia considerado como sem importância, como a biodiversidade, a conservação do meio-ambiente ou a importância dos sistemas não ocidentais de conhecimento, passaram a converter-se em um elemento central das políticas globais de desenvolvimento. Segundo esse autor o "desenvolvimento sustentável" não foi outra coisa que a reconversão pós-moderna (leia-se: neoliberal) do desenvolvimentismo moderno.

Assim, o desenvolvimento econômico hoje já não se mede pelos níveis materiais de industrialização senão pela capacidade de uma sociedade para gerar ou reservar capital humano. Enquanto que o desenvolvimentismo dos anos 1960 e 1970 somente 
levavam em conta o aumento de "capital físico", o desenvolvimento sustentável coloca no centro de sua preocupação a geração de "capital humano", ou seja, a promoção dos conhecimentos, aptidões e experiências que convertem a um ator social em sujeito economicamente produtivo. A possibilidade de converter o conhecimento humano em força produtiva, substituindo o trabalho físico e as máquinas, se transforma na chave da ideologia do desenvolvimento sustentável. Essa transformação é fundamental para entendermos a questão da educação e a centralidade do conhecimento na agenda das políticas para o setor.

No entanto é preciso advertir que, embora esse quadro desencadeia um movimento de relativa autonomia dos processos de financeirização sobre a esfera produtiva, essa autonomia é apenas aparente. É na esfera da produção que se cria a riqueza e a esfera financeira é alimentada pela riqueza criada através da mobilização de uma força de trabalho de múltiplos níveis de qualificação.

A ideologia para essa acumulação financeira é a de que a força de trabalho hegemônica hoje não está composta por trabalhadores materiais e sim por agentes capazes de produzir e administrar conhecimentos e informações, ou seja, a nova força de trabalho no capitalismo global se define por sua capacidade de manipular símbolos, o que significa que o modelo de pensamento de símbolos está se convertendo no modelo hegemônico de produção do capital. De acordo com esse modelo, a economia capitalista está sendo reorganizada com base no conhecimento que produzem ciências como a biologia molecular, a engenharia genética e por correntes de investigação como o genoma humano, a inteligência artificial e a biotecnologia. Para Escobar, o capitalismo "pós-moderno" é um regime biopolítico porque constrói a natureza e os corpos mediante uma série de biopráticas nas quais o conhecimento se torna fundamental. (ESCOBAR, 1999).

A partir dessa nova recomposição do capital corporificada pela ideologia do desenvolvimento sustentável e seu correlato: a sociedade do conhecimento, afirma-se que a informação e o conhecimento são a base da economia global. Dessa forma a falta de acesso a estes recursos se convertem na chave para explicar o subdesenvolvimento. Isso significa que não é mais o Estado o agente principal das mudanças que impulsionam o desenvolvimento econômico e sim os atores sociais através de sua apropriação de recursos cognitivos, pois eles lhes permitirão impulsionar uma economia centrada na informação e no conhecimento. 
Para Santiago Castro-Gómez, a ideologia do desenvolvimento sustentável pode formular-se da seguinte maneira: sem geração de "capital humano" não será possível superar a pobreza, pois esta se deve ao aumento da brecha do conhecimento entre os países. Segundo essa ideologia um país se desenvolverá somente quando aprender a utilizar e proteger seus ativos intelectuais, já que estes são a força propulsora de uma economia baseada nos conhecimentos. (CASTRO-GÓMEZ, 2005).

Todo esse processo ideológico gera aquilo que chamamos "sistema mundial de produção de conhecimento". Tal sistema, capitaneado pelos países do centro, articula empresa privada multinacional, grande orçamento público e grandes universidades públicas. Nessa imensa máquina de produção de conhecimentos, tais países mantém a supremacia tecnológica e epistemológica sobre os países da periferia através da ideologia do conhecimento. Como o conhecimento se transformou na maior força produtiva, e no capitalismo as forças produtivas são sempre privadas, a conclusão lógica desse silogismo é que o processo de produção de conhecimentos se tornou uma prerrogativa dos países centrais.

A aparente reconversão e abertura desse sistema mundial de produção de conhecimento aos conhecimentos não ocidentais na atualidade não nos deve levar ao engano. A lógica centro e periferia mantém sua hegemonia, agora mascarada pela farsa da globalização. O que está em jogo continua sendo a manutenção dos privilégios e a acumulação do capital nos países centrais através da troca desigual e sua consequência: a super exploração da força de trabalho nos países periféricos. A transformação dos sistemas de ensino é, para esse fim, de fundamental importância.

Tal reconversão modifica substancialmente a visão anterior. No paradigma anterior de desenvolvimento os sistemas não ocidentais de conhecimento eram vistos como inimigos do progresso. Para essa teoria, o processo de industrialização geraria condições para deixar atrás um tipo de conhecimento baseado em mitos e superstições superando-os pelo conhecimento científico-técnico da modernidade. Nesse paradigma moderno de desenvolvimento os conhecimentos não ocidentais, considerados pela lógica eurocêntrica como mitológicos e superiores, tinham que ser disciplinados ou excluídos.

No entanto, hoje, quando a reprodução do capital financeiro está baseada na informação e no conhecimento, onde a força produtiva por excelência é a ciência de ponta representada por ciências como a engenharia genética, biologia molecular, 
inteligência artificial e biotecnologia, os conhecimentos não ocidentais se tornam extremamente úteis ao projeto capitalista atual da biodiversidade. Dessa forma, a tolerância frente a diversidade cultural se converteu em um valor politicamente correto. A tal ponto que o índio passa por uma metamorfose impressionante: de um ser bestial e sem alma da conquista ao "guardião da biodiversidade" do mundo contemporâneo. De seres obstáculo para o desenvolvimento econômico da nação, agora são vistos como imprescindíveis para o desenvolvimento sustentável - desde que não lutem pelas suas terras - e seus conhecimentos são levados à categoria de "patrimônio da humanidade”. Processo muito bem descrito por Escobar:

\begin{abstract}
Una vez terminada la conquista semiótica de la naturaliza el uso sostenible y racional del médio ambiente se vuelve un imperativo. Aqui se encuentra la lógica subyacente de los discursos del desarrollo sostenible y la biodiversidade. Esta nueva capitalización de la naturaliza no descansa sólo sobre la conquista semiótica de territórios (en términos de reservas de bioviversidade); también exige la conquista semiótica de los conocimientos locales sobre el sostenimiento de la naturaliza. La biologia moderna empieza a descobrir que los sistemas locales de conocimiento son complementos úteles. (ESCOBAR, 2004, pg. 383).
\end{abstract}

Castro-Gómez enfatiza que aquilo que Escobar chama de "conquista semiótica” é a ressemantização, debaixo de um formato neoliberal, dos mecanismos coloniais que legitimam a exclusão dos conhecimentos outros que não os da modernidade. $O$ "reconhecimento" que se faz dos sistemas não ocidentais de conhecimentos não é epistêmico e sim pragmático. Eles são fundamentais para que os centros hegemônicos do capital possam manter sua supremacia sobre as periferias. Para esse autor ainda que os saberes das comunidades indígenas ou negras possam ser vistos como "úteis" para a conservação do meio ambiente, a distinção entre "conhecimento tradicional" e "ciência”, elaborada pela Ilustração no século XVIII, continua vigente. O primeiro segue sendo visto como um conhecimento anedótico, carente de método, enquanto que o segundo, apesar dos esforços transdisciplinares da última década, é tido ainda como o único conhecimento epistemologicamente válido. Para Castro-Gómez, esse processo é o rosto pós-colonial da “pós-modernidade”. (CASTRO-GÓMEZ, 2005)

Os conhecimentos produzidos pelas periferias do sistema agora são vistos como fundamentais, não como importantes em si mesmo, mas pela operacionalidade que possam ter na construção da nova força produtiva do capitalismo contemporâneo. Isso caracteriza a forma atual do colonialismo epistêmico, apenas um componente na nova 
forma de colonialidade, que se mantém sobre as periferias. A América Latina, assim como a África e a Ásia, continua a ser produtora de matéria prima para a "metrópole”, no nosso caso: epistêmico.

É através de várias formas, entre elas a nova forma de produzir, tendo a informação e o conhecimento como base, que o sistema capitalista atual mantém a lógica do centro/periferia. O sistema mundial de produção de conhecimento, que a partir do centro controla a produção desse conhecimento recolhido das periferias, precisa das "colônias epistêmicas" para esse fim. A investigação em engenharia genética é muito cara e está dominada por um pequeno número de empresas que operam desde esses países centrais, enquanto que seu “objeto de estudo”, a riqueza biológica da terra, se encontra nos países periféricos. Manter a hegemonia sobre as periferias é fundamental para a reprodução desse sistema, haja vista que a riqueza biológica da terra se concentra nas zonas tropicais e subtropicais de países pobres. Mais 4/5 partes da diversidade biológica do planeta se encontra em regiões do antes denominado terceiro mundo. Nosso país é particularmente afetado por essa lógica. $\mathrm{O}$ Brasil é o país mais biodiverso do mundo.

Assim, a lógica centro/periferia que caracterizou a conquista da América Latina no século XVI, e que se reconfigura com o processo de industrialização na primeira metade do século XX, ainda continua vigente. Ainda que sob outras capas, entre elas o epistemológico, o centro hegemônico eurocêntrico primeiro e americano depois, mantém sua dominação sobre as periferias do sistema. O "paradigma eurocêntrico" mapeado por Enrique Dussel continua vigente e a dependência e o subdesenvolvimento da América Latina ainda são questões prementes.

\section{CONCLUSÃO}

A superação desse sistema colonial é de fundamental importância para o estabelecimento de um processo educacional crítico convertido em rosto latinoamericano. A lógica centro/periferia, vigente desde a conquista, através de um capitalismo imperialista e colonial não é coisa do passado. Hoje ela se manifesta de uma forma mais aguda porque invisível a um olhar superficial. A ideologia da sociedade do conhecimento produz um sistema mundial de produção de conhecimento que, ao recolher os conhecimentos da periferia do sistema, concentra em seu centro 
produtivo, composto por financiamento público/privado e Universidades, as condições para o registro de patentes e, com isso, a acumulação e reprodução do capital.

Os sistemas de ensino que vigoram nas periferias, com a anuência consciente das elites internas e dos inconscientes colonizados, reforçam esse sistema mundial de produção de conhecimentos. Tudo é feito para que a supremacia epistêmica e tecnológica mantenha o padrão de acumulação dos países centrais. As reformas educacionais na América Latina, desde o final do século passado, caminham sempre na mesma direção, ou seja, produzir a qualificação mínima para a super exploração da força de trabalho, já que este precisa ser redimensionado para atender as exigências atuais da acumulação do capital, e conjuntamente, manter a condição de colônias epistêmicas para que os centros produtores de conhecimento possam, através dos conhecimentos recolhidos das periferias, registrar patentes e manter assegurado a acumulação e reprodução do capital.

Assim, é nossa opinião que a superação dessa lógica colonial epistêmica passa necessariamente pela superação da lógica do capital. A educação vigente é parte integrante da sociabilidade capitalista e nos parece ingênuo querer mudar a educação mantendo seu suporte material. Propostas como educação cidadã, formação integral, educação crítica (uma criticidade tão ampla que não se sabe bem o que quer dizer), educação libertadora e/ou humanizadora e outras do gênero tocam apenas a superfície do problema: àquilo que Marx chamou de emancipação política. Para um país periférico e dependente é preciso mais. É preciso a consciência de que uma educação nos moldes da emancipação humana, verdadeiramente libertadora, só terá vigência em outra matriz de sociabilidade. Podemos e devemos lutar por melhorias, mas tendo sempre em mente que não são a meta final. A meta final é a emancipação humana, uma sociabilidade baseada não no trabalho abstrato, mas no trabalho associado, que só terá vigor pleno em uma outra sociabilidade. Por isso, o legado do maestro caraquenho permanece atual: ou inventamos, ou erramos.

\section{REFERÊNCIAS}

CASTRO-GÓMEZ, Santiago. La Poscolonialidad explicada a los niños. Bogotá: Universidad Javeriana, 2005.

DURAN, Maximiliano. El concepto de ciudadano en el pensamiento de Simón Rodríguez: igualdad y universalidade. Revista anual de la Unidad de Historiografia e Historia de las ideas. Vol. 12. N. 1. Mendonza. 2010. 
DUSSEL, Enrique. 1492: o encobrimento do outro. Petrópolis: Vozes, 1993.

DUSSEL, Enrique. Ética da libertação: na idade da globalização e da exclusão. Petrópolis: Vozes, 2002.

ESCOBAR. La invención del Tercer Mundo. Bogotá: Norma, 1999.

ESCOBAR, Arturo. Mas allá del tercer mundo: Globalidad imperial, colonialidade global y movimentos antiglobalización. Nômadas 20: 86-100, 2004.

GROSFOGUEL, Ramón. A estrutura do conhecimento nas universidades ocidentalizadas: racismo/sexismo epistêmico e os quatro

genocídios/epistemicídios do longo século XVI. Brasília: Revista Estado e Sociedade, volume 31, número 1, janeiro/abril, 2016.

LANDER, Edgar. La colonialidade del saber. Eurocentrismo y ciências sociales. Perspectivas latino-americanas. Clacso-Unesco: Buenos Aires, 2000.

QUIJANO, Aníbal. Colonialidade do poder, eurocentrismo e América latina. Buenos Aires: Clasco, 2015.

MARINI, Ruy Mauro. Dialética de la dependência. México: Editora Era, 1990.

RODRÍGUEZ, Simón. Obras Completas. TOMO I. Caracas: Reedición bajo los auspicios de la Presidencia de la República, 1999.

RODRÍGUEZ, Simón. Obras Completas._TOMO II. Caracas: Reedición bajo los auspicios de la presidencia de la república, 1999.

RODRÍGUEZ, Simón. Inventamos ou erramos. Belo horizonte: Autêntica Editora, 2016.

SANTOS, Boaventura, MENESES, Maria Paula. Epistemologias do Sul. Coimbra: Edições Almedina S/A, 2009.

Sobre o autor

José Newton Tomazzoni Tavares - Professor do Departamento de Filosofia da Pontifícia Universidade Católica de Minas Gerais. Graduação em Filosofia pela Pontifícia Universidade Católica de Minas Gerais. Mestre e Doutor em Educação pelo Programa de Pós-graduação em Educação da Pontifícia Universidade Católica de Minas Gerais. E-mail: jnewtont@uol.com.br 